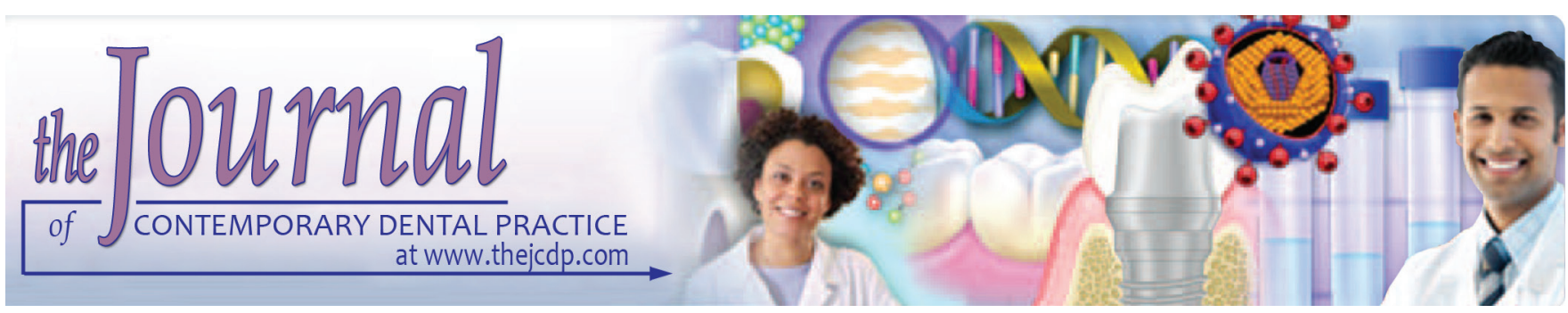

\title{
Surface Hardness of Dental Composite Resin Restorations in Response to Preventive Agents
}

\author{
Khalid H Al-Samadani
}

\begin{abstract}
Introduction: To assess the impact of using preventive mouthwash agents on the surface hardness of various resins composites.
\end{abstract}

Materials and methods: Hundred specimens were prepared from five types of composite resin material in a Teflon mold. Five specimens from each type of restorative materials (Herculite XRV Ultra, Estelite $\Sigma$ Quick, Z Hermack, Versa Comp Sultan, and Empress Direct IPS) were evaluated posttreatment with immersion in four types of preventive mouthwashes gels and rinses group 1: Flocare gel ( $0.4 \%$ stannous fluoride), group 2: Pascal gel (topical APF fluoride), group 3: Pro-relief mouthwash (Na fluoride), and group 4: Plax Soin mouthwash (Na fluoride) - at $37^{\circ} \mathrm{C}$ in a dark glass container at 24,48 , and 72 hours. Surface hardness measurement was made for each tested material. Statistically, we analyzed the mean values with one-way analysis of variance (ANOVA) and Tukey's test, with significance level of $p<0.05$.

Results: All composite resin materials showed decrease in their surface hardness with the time elapsed $(24,48$, and 72 hours) postimmersion in the preventive mouthwashes and gels except the Herculite XRV Ultra and Versa Comp Sultan materials. Flocare gel group showed increase in the surface hardness after 48 hours of immersion than the other periods and in Estelite $\Sigma$ Quick after 72 hours. There was significant differences in all materials tested with the immersion in the preventive mouthwashes and gels, such as Flocare gel ( $0.4 \%$ stannous fluoride), Pro-relief mouthwash ( $\mathrm{Na}$ fluoride), and Plax Soin mouthwash (Na fluoride) except Pascal gel (topical APF fluoride) $(p>0.05)$, at time intervals mentioned earlier $(p<0.05)$.

Conclusion: The effect of preventive mouthwashes and gels on resin composite materials was decreased surface hardness with the time elapse of immersion for all materials except the

Department of Restorative Dental Sciences, College of Dentistry Taibah University, Madina, Kingdom of Saudi Arabia

Corresponding Author: Khalid H Al-Samadani, Department of Restorative Dental Sciences, College of Dentistry, Taibah University, Madina, Kingdom of Saudi Arabia, e-mail: kalsamadani@gmail.com
Flocare gel group, which contains $0.4 \%$ stannous fluoride as a preventive ingredient increases the surface hardness after 48 $\mathrm{h}$ for Herculite XRV Ultra and Versa Comp Sultan and Estelite $\Sigma$ Quick after 72 hours.

Clinical significance: The preventive agents in the form of mouthwash and gel are used to prevent oral diseases that affect the surface hardness of composite resin, and this leads to occlusion, color stability, and surface roughness.

Keywords: Composite resin, Empress Direct IPS, Flocare gel, Preventive mouthwashes, Surface hardness.

How to cite this article: Al-Samadani KH, Surface Hardness of Dental Composite Resin Restorations in Response to Preventive Agents. J Contemp Dent Pract 2016;17(12):978-984

Source of Support: Nil

Conflict of Interest: None

\section{INTRODUCTION}

Composite resins are important materials used for restoration procedures. These materials need long-term durability while performing in oral cavity. ${ }^{1}$ However, these materials have some limitations, such as polymerization shrinkage, the necessity for procedures to avoid contact with humidity and chemical ingredients acids, and fluoride particles as a preventive anticaries, which lead to low abrasion strength and decrease in surface hardness. ${ }^{2}$ Resin composites are composed of a polymer resin matrix, reinforced nanofillers, and silane coupling agents. These nanocomposites have beneficial esthetic properties as well as better mechanical properties, hence making these composites a material of choice for anterior direct restorations. ${ }^{3}$

In clinical scenario, composite resin restorative materials degradation cannot be considered as a sole parameter; instead, it is the result of complex reactions involving various factors. ${ }^{4}$ Mouthwash rinses are frequently used as preventive agents and have recently become popular choice in preventing and controlling dental caries and 
periodontal diseases, without the prescription of the dentists. ${ }^{5-8}$ The mouthwashes consist of water, antimicrobial agents, salts, fluoride preventive anticaries agents, and some types of alcohol. ${ }^{9,10}$ Due to variable concentrations of such agents in mouthwashes, $\mathrm{pH}$ of mouth is affected. ${ }^{4}$ However, the effect of these ingredients on the composite resin polymeric matrix is more susceptible to degradation. ${ }^{11-13}$ As well as the changes in the inorganic phase may affect the materials physical properties, including roughness and the surface hardness. ${ }^{7,14,15}$

A reduction in the surface hardness with the daily use of preventive mouthwashes containing different types of fluoride anticaries as preventive agents can also affect other properties, such as the wear resistance for the composite resin restoration materials, ${ }^{16}$ which may result in increased surface roughness of the material. ${ }^{17,18}$

Some previous studies reported the controversial findings regarding the role of mouthwashes containing fluoride ingredients as anticaries preventive agents on the properties (roughness, hardness) of composite resin materials. ${ }^{4}$

Thus, this study is aimed at to investigate the role of mouthwashes containing different types of fluoride ingredients as anticaries agents on the surface hardness of hybrid, microhybrid, and nanohybrid resin-based composite materials, after three times of immersion in mouthwashes at 24, 48, and 72 hours.

\section{MATERIALS AND METHODS}

Five resin composite restorative materials, Herculite XRV Ultra, Estelite $\Sigma$ Quick resin-based composite Tokuyama, Z Hermack microhybrid composite, Versa Comp Sultan Universal-hybrid composite, and Empress Direct IPS resin composite Ivoclar Vivadent, were evaluated for their surface hardness in response to four preventive mouthwashes and gels - group 1: Flocare gel (0.4\% stannous fluoride), group 2: Pascal gel (topical APF fluoride), group 3: Pro-relief mouthwash ( $\mathrm{Na}$ fluoride), and group 4: Plax Soin mouthwash (Na fluoride). The esthetic restorative materials and preventive mouthwashes and gels (agents) used in this research study are shown in Table 1.

Hundred specimens of the esthetic restorative materials were prepared in which five specimens from each restorative composite material of different aging groups were evaluated.

According to the manufacturer's instructions, all specimens of the restorative materials were dispensed, manipulated, and polymerized.

\section{Molds Fabrication}

Teflon molds, measuring $6 \mathrm{~mm}$ internal diameter and $3 \mathrm{~mm}$ height, were used to produce the specimens.

\section{Specimens Preparation}

Open end of each Teflon mold was placed on a glass microscope slide, overlaid with a cover glass $22 \mathrm{~mm} \times 22$ $\mathrm{mm}$ (BDH Borosilicate glass) to act as a separator. Their dual function was to provide compaction of the materials into a flat surface and to act as a separator between the mold and the glass microscope slide. The layering technique was used, especially in the preparation of the specimens of the light-activated dental restorative filling materials and compacting with a plastic spatula, after which the restorative filling materials were irradiated with a 20-second pulse from a light-curing light-emitting diode unit. The mold was completely filled with the material using this stepwise method and irradiated at each stage with 20 seconds light pulses. All samples were polished using 3M Sof-Lex discs and stored for 24 hours in the deionized distilled water $\left(37^{\circ} \mathrm{C}\right)$ before baseline hardness test. Vickers hardness numbers were determined using a microhardness tester (Micronet 6040, Buehler, USA).

Table 1: Details of composite resin materials and preventive mouthwash used in this study

\begin{tabular}{|c|c|c|c|}
\hline Material & Type & Shade & Manufacturer \\
\hline Herculite $^{\mathrm{TM}}$ XRV Ultra & Nano-hybrid-composite & A3 & $\begin{array}{l}\text { Kerr italia, S.rl Via passanti, } 332 \text { 1-84018 } \\
\text { Scafati (SA), Italy }\end{array}$ \\
\hline Estelite $\Sigma$ Quick & Resin-based dental restorative material & A3 & $\begin{array}{l}\text { Tokuyama Dental Corporation 38-9, Taitou } \\
\text { 1-chome, Taitou-ku, Tokyo, Japan }\end{array}$ \\
\hline Z Hermack & Universal microhybrid resin-based composite & A3 & Made in - Germany \\
\hline Versa Comp Sultan & Universal-hybrid composite & A3 & $\begin{array}{l}\text { SULTAN } 411 \text { Hackensack Avenue, } 9^{\text {th }} \text { Floor } \\
\text { Hackensack, NJ }\end{array}$ \\
\hline Empress ${ }^{\circledR}$ Direct IPS & Direct refill enamel & A3 & Ivoclar Vivadent. Made in Liechtenstein \\
\hline Flocare gel & $\begin{array}{l}\text { Effective in helping reduce decay and } 0.4 \% \\
\text { stannous fluoride }\end{array}$ & - & Dentamerica ${ }^{\circledR}$ USA \\
\hline Pascal gel & $\begin{array}{l}\text { Gel anticavity topical APF* preventive } \\
\text { treatment gel }\end{array}$ & - & $\begin{array}{l}2929 \text { NE Northup Way, Bellevue, WA } 98004 \text {, } \\
\text { USA }\end{array}$ \\
\hline Pro-relief mouthwash & Colgate mouthwash & - & Colgate made in Thailand \\
\hline Plax Soin mouthwash & Colgate mouthwash & _- & Colgate made in Thailand \\
\hline
\end{tabular}




\section{Immersion of the Specimens}

The baseline of surface hardness was measured after storing in the distilled water and each specimen was thoroughly rinsed for 120 seconds. The prepared samples were immersed in $100 \mathrm{~mL}$ of tested preventive mouthwashes and gels for 24 hours in a dark bottle, which was found to be equivalent to 2 years of daily mouthwash use, 2 min rinse per day, and 12 hours of storage is equivalent to 1 year of rinsing ${ }^{4}$; therefore, the time periods of immersions in the groups within this study simulate to 2,4 , and 6 years. The specimens of all five tested composite resins were immersed in the four groups, Groups 1, 2, 3, and 4 , were stored at $37^{\circ} \mathrm{C}$, and were shaken using an orbital rotational table every 3 hours to provide homogeneity. Post each time of immersion for 24, 48, and 72 hours under the same test conditions, samples were rinsed using copious amount of distilled water and dried using absorbable tissue. The surface hardness measurement was taken.
The mean of the obtained results for the tested materials within different storage times is shown in Tables 2 to 5. The mean was calculated from the specimens of each tested materials immersed with the preventive mouthwashes and gels groups at different interval times.

The mean values of various materials at different immersing times were compared by one-way analysis of variance (ANOVA), and multiple comparisons of mean were performed using Tukey's test and the level of $p<0.05$ was regarded as significant.

\section{RESULTS}

The mean hardness values of tested materials immersed in a period of 24,48 , and 72 hours after exposure to different groups of the preventive mouthwashes and gels are summarized in Tables 2 to 5 and Graphs 1 to 4 .

Table 2: Surface hardness for tested composite resin materials immersed in Flocare anticaries gel for different aging periods

\begin{tabular}{|c|c|c|c|c|c|}
\hline Materials & Before aging & $\begin{array}{l}\text { Surface hardness } \\
\text { after } 24 \text { hours }\end{array}$ & $\begin{array}{l}\text { Surface hardness } \\
\text { after } 48 \text { hours }\end{array}$ & $\begin{array}{l}\text { Surface hardness } \\
\text { after } 72 \text { hours }\end{array}$ & $\begin{array}{l}\text { Significant } \\
\text { level }\end{array}$ \\
\hline Herculite $^{\mathrm{TM}}$ XRV Ultra & 47.166 & 44.5 & 48.75 & 45.08 & $p<0.028$ \\
\hline Estelite $\Sigma$ Quick & 54 & 53.33 & 51.25 & 53.44 & \\
\hline Z Hermack & 73.58 & 58.75 & 57.55 & 52.44 & \\
\hline Versa Comp Sultan & 68.91 & 58.58 & 61.66 & 53.33 & \\
\hline Empress ${ }^{\circledR}$ Direct IPS & 65.5 & 54.08 & 52.166 & 46.83 & \\
\hline
\end{tabular}

Table 3: Surface hardness for tested composite resin materials immersed in Pascal anticaries gel, for different aging periods

\begin{tabular}{llllll}
\hline Materials & $\begin{array}{l}\text { Before } \\
\text { aging }\end{array}$ & $\begin{array}{l}\text { Surface hardness } \\
\text { after 24 hours }\end{array}$ & $\begin{array}{l}\text { Surface hardness } \\
\text { after 48 hours }\end{array}$ & $\begin{array}{l}\text { Surface hardness } \\
\text { after 72 hours }\end{array}$ & $\begin{array}{l}\text { Significant } \\
\text { level }\end{array}$ \\
\hline Herculite $^{\text {TM }}$ XRV Ultra & 49.08 & 27.75 & 19.75 & 11.5 & $\mathrm{p}=0.689$ \\
Estelite $\Sigma$ Quick & 55.66 & 42.66 & 40.9 & 40.08 & \\
Z Hermack & 80.91 & 32.22 & 31.92 & 26.416 \\
Versa Comp Sultan & 68.5 & 42.25 & 29.33 & 20.166 \\
Empress $^{\circledR}$ Direct IPS & 60.5 & 39.83 & 30.33 & 21.5 & \\
\hline
\end{tabular}

Table 4: Surface hardness for tested composite resin materials immersed in Pro-relief mouth reins for different aging periods

\begin{tabular}{llllll}
\hline Materials & $\begin{array}{l}\text { Before } \\
\text { aging }\end{array}$ & $\begin{array}{l}\text { Surface hardness } \\
\text { after 24 hours }\end{array}$ & $\begin{array}{l}\text { Surface hardness } \\
\text { after 48 hours }\end{array}$ & $\begin{array}{l}\text { Surface hardness } \\
\text { after 72 hours }\end{array}$ & $\begin{array}{l}\text { Significant } \\
\text { level }\end{array}$ \\
\hline Herculite $^{\text {TM }}$ XRV Ultra & 47.75 & 44.58 & 43.25 & 41.58 & $\mathrm{p}<0.012$ \\
Estelite $\Sigma$ Quick & 56.75 & 54.67 & 51.25 & 47.58 & \\
Z Hermack & 69.75 & 60.09 & 58.42 & 54 & \\
Versa Comp Sultan & 65.166 & 64.33 & 58.91 & 50.166 & \\
Empress $^{\circledR}$ Direct IPS & 65.91 & 50.25 & 49.91 & 48.11 & \\
\hline
\end{tabular}

Table 5: Surface hardness for tested composite resin materials immersed in Plax Soin mouth reins for different aging periods

\begin{tabular}{lllll}
\hline Materials & $\begin{array}{l}\text { Before } \\
\text { aging }\end{array}$ & $\begin{array}{l}\text { Surface hardness } \\
\text { after 24 hours }\end{array}$ & $\begin{array}{l}\text { Surface hardness } \\
\text { after 48 hours }\end{array}$ & $\begin{array}{l}\text { Surface hardness } \\
\text { after 72 hours }\end{array}$ \\
\hline Herculite ${ }^{\mathrm{TM}}$ XRV Ultra & 45.55 & 42.44 & 40 & 38.25 \\
level & p<0.000 \\
Estelite $\Sigma$ Quick & 55.91 & 52.416 & 49.5 & 49.01 \\
Z Hermack & 76.33 & 61.99 & 60.9 & 59.21 \\
Versa Comp Sultan & 71.25 & 66.22 & 64.99 & 64.0 \\
Empress $^{\circledR}$ Direct IPS & 63.5 & 55.41 & 54.33 & 54 \\
\hline
\end{tabular}




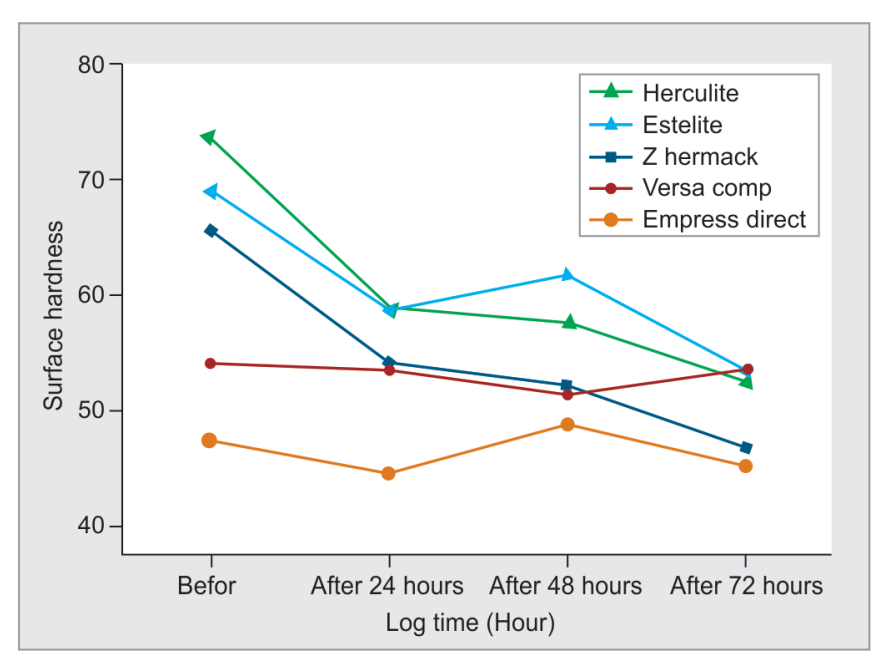

Graph 1: Surface hardness values of composite resin materials at different storage times immersed in Flocare anticaries gel

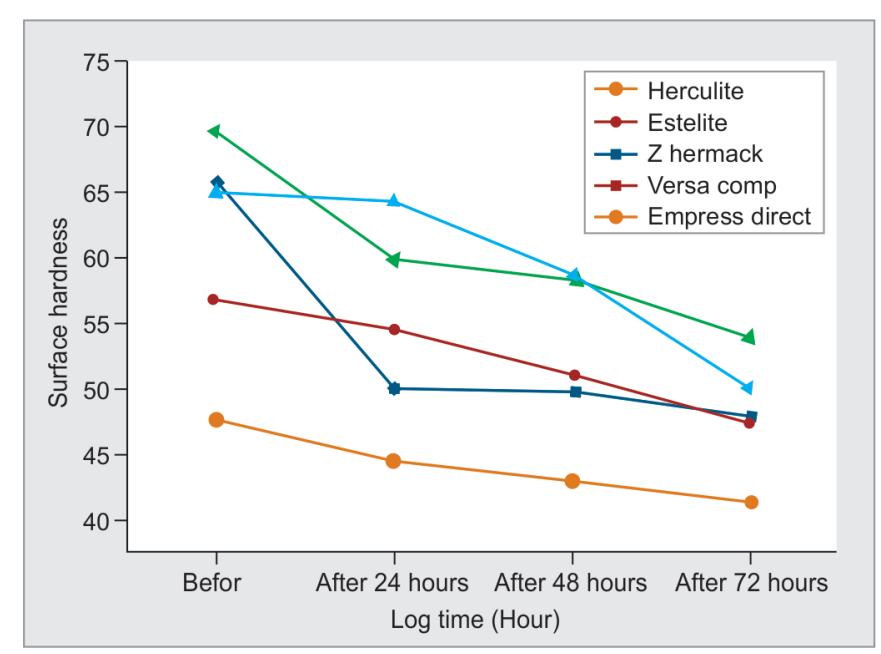

Graph 3: Surface hardness values of composite resin materials at different storage times immersed in Pro-relief mouth rinse solution

Comparing the surface hardness values for all the tested materials between the values of the baseline before the immersion in the mouthwashes solutions and gels showed decreased surface hardness after the immersion periods.

The surface hardness of all materials immersed for 24,48 , and 72 hours in the mouthwashes and gels was analyzed statistically using ANOVA followed by the Tukey's test and were found significant differences in surface hardness between the three different immersion periods of times for each group ( $\mathrm{p}<0.05)$, except for the Pascal gel group $(p>0.05)$ (Tables 2 to 5$)$.

The surface hardness changes for all materials in immersion periods of 24,48 , and 72 hours exhibited by the following groups of immersions for the preventive agents - Flocare gel, Pascal gel, Pro-relief mouthwash, and Plax Soin mouthwash - were significantly different except with Pascal gel.

The surface hardness of all the materials immersed in the group 1 Flocare gel with the different periods of

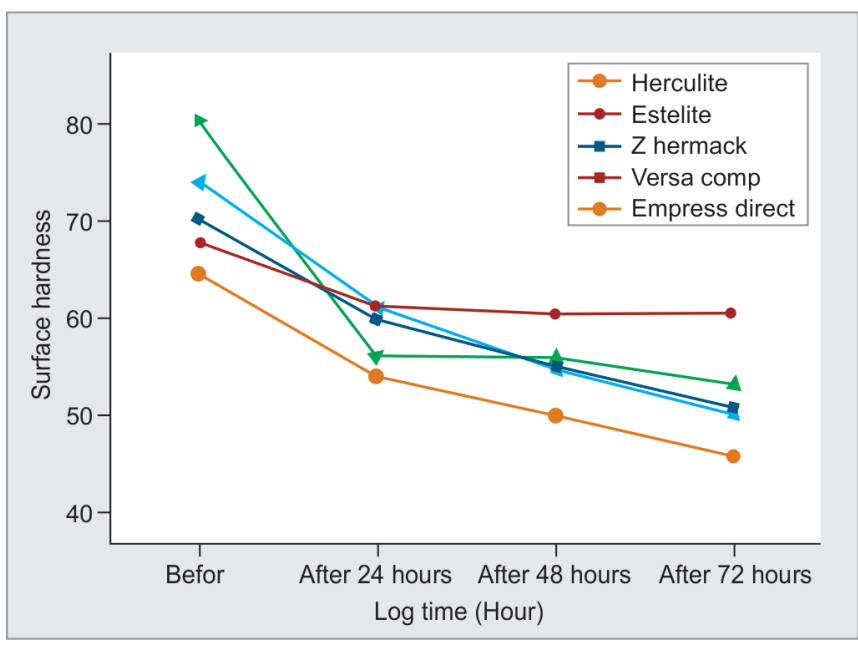

Graph 2: Surface hardness values of composite resin materials at different storage times immersed in Pascal anticaries gel

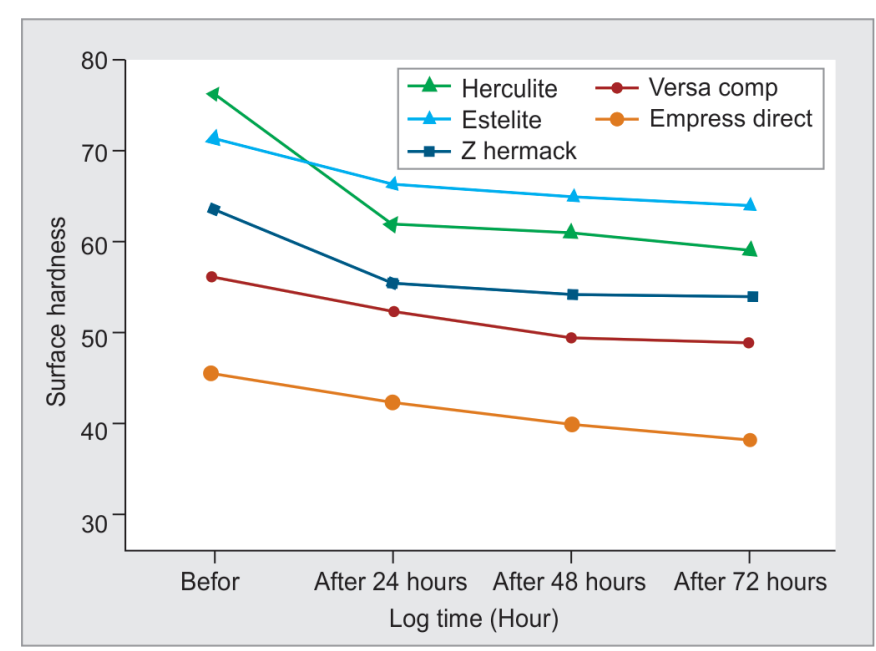

Graph 4: Surface hardness values of composite resin materials at different storage times immersed in Plax Soin mouth rinse solution

immersion times - 24, 48, and 72 hours - has decreased, while for the immersion period of 48 hours there was decrease in all the materials except for the materials Herculite XRV Ultra and Versa Comp Sultan, where the surface hardness has increased from the period of 24 hours. In addition, during the period of 72 hours of immersion in this group, all composite materials surface hardness has decreased compared with the period of 48 hours, except the Estelite $\Sigma$ Quick material which showed shift to increase in the surface hardness compared with the 24 and 48 hours of immersion time. A significant change in hardness was observed in case of all resin composites in this immersion group of Flocare gel $(\mathrm{p}<0.028)$ (Table 2 and Graph 1$)$.

In the group 2 Pascal gel, all the composite resin materials showed decrease in their surface hardness with the time elapse of 24,48 , and 72 hours, and there was no significant difference $(p=0.689)$ in materials within the different time elapsed of the Pascal gel immersion group 
where all the materials had decrease in their surface hardness in the same manner of increased times of immersion (24, 48, and 72 hours) (Table 3 and Graph 2).

While, in the group 3 Pro-relief mouthwash, all composite resin materials exhibited decrease in their surface hardness with different times of immersion of 24, 48, and 72 hours within this group, all materials showed significant difference $(\mathrm{p}<0.012)$ between all materials for increasing immersion times (Table 4 and Graph 3).

The group 4 Plax Soin mouthwash shows decrease in surface hardness of all materials, but highly significant differences $(p<0.000)$ between all the materials of composite resin with increasing immersion times of 24, 48 , and 72 hours were observed within this group. The results are shown in Table 5 and Graph 4.

\section{DISCUSSION}

Mouthwashes have adverse effect on the surface hardness, with respect to the presence of some amount of water in the mouthwashes solutions, ${ }^{19}$ which leads to adverse effect of water sorption and softening of material and decreasing hardness. ${ }^{19}$ Due to the hygroscopic expansion, there is accumulation of water molecules in the microspaces. Such accumulation of water results in the reduction in the mechanical properties, such as hardness, ${ }^{20-22}$ as well as leaching out component as fillers. The homogeneous distributions of the fillers in the resin matrix improve the material's functioning in the humid environment. In contrast, voids at filler-matrix interface are likely to enhance water absorption by material. ${ }^{20}$ The use of mouthwash rinses may result in a chemical softening that would have consequences on the clinical resilience of composite resins. ${ }^{23}$ The nanoclusters of the filler particles reduce interstitial space of the filler particles, which is likely to improve the properties, such as hardness, sorption, and surface roughness. ${ }^{24}$

The surface hardness test is important because it may affect the surface properties of esthetics materials and teeth. ${ }^{25-27}$ The strength and rigidity of materials are related to the surface hardness property. ${ }^{28}$ Some of the previous studies reported that alcohol-free and alcoholcontaining mouthwashes influences the surface properties (hardness) of resin composites. ${ }^{23,29}$ In this in vitro study, the esthetic composite resin materials of different compositions of hybrid, microhybrid, and nanohybrid, which is resin-based material immersed in the preventive mouthwashes and gels at different interval time elapse of 24,48 and 72 hours, was found to be equivalent to $2 \mathrm{~min} /$ day for 24 hours for 2 years of daily mouthwash use. ${ }^{4}$ Therefore, the time periods of immersions in the groups mentioned within this study simulate to 2, 4, and 6 years.

The therapeutic antibacterial and anticarious role of fluoride have been well documented ${ }^{30,31}$ and commonly added to dental restorative materials ${ }^{30-33}$ and various dental care products. ${ }^{31}$ All the preventive agents used in this study contain different types of fluoride particles in their composition as preventive ingredients, such as 0.4 stannous fluoride (Flocare gel), APF fluoride (Pascal gel), and Na fluoride (Pro-relief mouthwash, Plax Soin mouthwash). Fluoride particles have adverse effect on the resin matrix of the materials due to the monomers content in the resin matrix and the type of fluoride particles content used as preventive agents. ${ }^{34,35}$ These fluoride particles were used to prevent and control caries as antidecays, which leads to chemical softening and affect the strength and rigidity of the material, thereby decreasing the surface hardness of the composite resin restorations. ${ }^{36}$

Low $\mathrm{pH}$ of active ingredients of mouthwashes may influence the surface hardness, wear, and color. ${ }^{7,23}$ The acidity may change the polymeric matrixes of composite resin affecting dimethacrylate monomer present in their compositions. ${ }^{4}$ The previous study suggested that by lowering the solutions $\mathrm{pH}$, there is production of methacrylic acid that results in the sorption and hygroscopic expansion as a consequence of enzymatic hydrolysis and biodegradation. ${ }^{4,15}$ The findings of this study showed that the hardness of different resin composites prior to (baseline) and after exposure to the four mouthwash rinses and gels for 24, 48, and 72 hours are summarized in Tables 2 to 5 and graphically represented in Graphs 1 to 4 .

The surface hardness changes exhibited by all the five tested composite resin materials were significantly different for the Flocare gel group, Pro-relief mouthwash, and Plax Soin mouthwash groups ( $\mathrm{p}<0.05)$, except for the Pascal gel group whose $\mathrm{p}$-value was $>0.05$, during the three time periods. The surface hardness of the five different types of resin-based hybrid, microhybrid, and nanohybrid composite esthetic materials decreased in each immersion agents groups with the increasing time of immersion, except for the group 1 Flocare gel, where the results varied for two materials post 48 hours while for the third material post 72 hours there was shift to increase in surface hardness. The results of group 1 Flocare gel, which contains $0.4 \%$ stannous fluoride in their composition as preventive agent (antidecay), at different periods of immersion times of 24,48 , and 72 hours showed decrease for all the materials, except for 48 hours which varied between the materials. The Estelite $\Sigma$ Quick, Z Hermack, and Empress Direct IPS showed decrease in surface hardness at this 48 hours' time period except for the materials Herculite XRV Ultra and Versa Comp Sultan, where the surface hardness has increased than at the period of 24 hours. While during the period of 72 hours of immersion, in this group, all composite 
materials were decreased than the period of 48 hours except the Estelite $\Sigma$ Quick material which shift back to increase the surface hardness than the 24 and 48 hours of immersion time. Statistically analysis showed significant changes of the surface hardness values were observed for the all composite resin materials in this immersion group of Flocare gel with different periods $(\mathrm{P}<0.028)$ (Table 2 and Graph 1).

In the group 2 Pascal gel, which contains APF fluoride and $\mathrm{Na}$ fluoride in their composition as preventive ingredients (anti-decay), all the composite resin materials showed decrease in their surface hardness with the time elapse of 24, 48, and 72 hours. Statistical analysis showed no significant changes in the surface hardness values were observed for all the composite resin materials $(\mathrm{P}=0.689)$ between the materials within the different time elapse of the Pascal gel immersion group, where all the materials showed decrease in their surface hardness in the same manner of increasing times of immersion $(24,48$, and 72 hours) respectively to preventive ingredients (Table 3 and Graph 2).

While, in the group 3 Pro-relief mouthwash that contains Na fluoride as a preventive ingredients in their composition, all composite resin materials exhibited decreased surface hardness with the increase in different times of immersion of 24,48 , and 72 hours for this group, all treated materials statistically showed significant difference $(\mathrm{P}<0.012)$ between all materials with the increasing times of immersion (Table 4 and Graph 3).

The Group 4 Plax Soin mouthwash contains $\mathrm{Na}$ fluoride substance as a preventive active ingredients that result in decrease in surface hardness for all tested materials, and statistical analysis showed highly significant differences $(p<0.000)$ between all the materials of composite resin and with the increasing times of immersion of 24, 48, and 72 hours within this group (Table 5 and Graph 4).

As in the previous studies finding, it was observed that alcohol-free mouth rinses showed decrease in the surface hardness, containing sodium fluoride as preventive ingredients within the composition of the mouth rinse. ${ }^{2,14,34,37,38}$ It demonstrates that this study findings has agreement with the previous studies. ${ }^{2,4,7,16,23,34,35}$

As the immersion time increases, surface hardness decreases because of the increased interaction between the component of the preventive agent and the resin due to enhanced penetration of mouthwash component in the resin. Comparing the in vitro studies to the in vivo, clinically, the effect of the preventive agents on the composite resin restoration materials may differ, whereas the clinical studies may produce better results compared to in vitro studies not considering factors, such as $\mathrm{pH}$ of the oral environment, foods, drinks, and oral saliva. ${ }^{7}$

\section{CONCLUSION}

Within the limitations imposed in this study, it can be concluded that the hardness of various composites changed significantly from each other. All types of mouthwash gels and rinses used in this in vitro study affected the surface hardness of the tested resin composites, where the resin composites showed decrease in their surface hardness within the varied times and with the increasing immersion times (24, 48, and 72 hours), except for the group 1 Flocare gel, which contains 0.4 stannous fluoride preventive ingredients. At the 48 hours of immersion (simulated to 4 years of use of mouthwash) for the Herculite XRV Ultra and Versa Comp Sultan materials, the surface hardness increased than the other immersion times, while Estelite $\Sigma$ Quick increases at 72 hours.

The APF and Na fluorides, which are preventive ingredients in the other preventive agents groups, showed decrease in the surface hardness for the tested resin composites with the increasing immersion times. The combination between the active ingredients within the mouthwash might increase their adverse effect on the composite resin material.

\section{REFERENCES}

1. Al-Samadani KH. Color stability of restorative materials in response to Arabic coffee, Turkish coffee and Nescafe. J Contemp Dent Pract 2013 Jul;14(4):681-690.

2. Antony Fernandez RA, El Araby M, Siblini M, Al-Shehri A. The effect of different types of oral mouth rinses on the hardness of silorane-based and nano-hybrid composites. Saudi J Oral Sci 2014;1(2):105-109.

3. Ferracane J. Current trends in dental composites. Crit Rev Oral Biol Med 1995;6(4):302-318.

4. Miranda DA, Boertldo CES, Aguiar FHB, Lima DANL, Lovadino JR. Effects of mouthwashes on Knoop and surface roughness of dental composites after different immersion times. Braz Oral Res 2011 Mar-Apr;25(2):168-173.

5. GagariE,KabaniS. Adverse effects of mouthwash use. Areview. Oral Surg Oral Med Oral Pathol Oral Radiol Endod 1995 Oct; 80(4):432-439.

6. Ateyah NZ. The effects of different mouthrinses on microhardness of tooth-coloured restorative materials. J Pak Dent Assoc 2005;14(3):150-153.

7. Awliya WY. The effect of mouthrinses on surface hardness and weight change of some aesthetic restorative material. J Pak Dent Assoc 2005;14:84-89.

8. Yap AU, Chew CL, Ong LF, Teoh SH. Environmental damage and occlusal contact area wear of composite restoratives. J Oral Rehabil 2002 Jan;29(1):87-97.

9. Mitra SB, Wu D, Holmes BN. An application of nanotechnology in advanced dental materials. J Am Dent Assoc 2003 Oct;34(10):1382-1390.

10. Sarret DC, SÖderholm JM, Batich CD. Water and abrasive effects on three-body wear of composites. J Dent Res 1991 Jul;70(7):1074-1081.

11. Okada K, Tosaki S, Hirota K, Hume WR. Surface hardness change of restorative filling materials stored in saliva. Dent Mater 2001 Jan;17(1):34-39. 
12. Gürdal P, Güniz Akdeniz B, Hakan Sen B. The effects of mouthrinses on microhardness and colour stability of aesthetic restorative materials. J Oral Rehabil 2002 Sep;29(9): 895-901.

13. Almeida GS, Poskus LT, Guimaräes JG, da Silva EM. The effect mouthrinses on salivary sorption, solubility and surface degradation of nanofilled and hybrid resin composite. Oper Dent 2010 Jan-Feb;35(1):105-111.

14. Cavalcanti AN, Mitsui FH, Ambrosano GM, Mathias P, Marchi GM. Effect of different mouthrinses on Knoop hardness of a restorative composite. Am J Dent 2005 Dec;18(6): 338-340.

15. Örtengren U, Anddersson F, Elgh U, Terselius B, Karlsson S. Influence of $\mathrm{PH}$ and storage time on the sorption and solubility behaviour of three composite resin materials. J Dent 2001 Jan;29(1):35-41.

16. De Mores PIC, das Neves LE, de Souza CK, Parolis A, Barbosa dos Santos N. A comparative effect of mouthwashes with different alcohol concentrations on surface hardness, sorption and solubility of composite resins. Oral Health Dent Manage 2014 Jun;13(2):502-506.

17. Borges MA, Matos IC, Mendes LC, Gomes AS, Miranda MS. Degradation of polymeric restorative materials subjected to a high caries challenge. Dent Mater 2011 Mar;27(3):244-252.

18. Craig, R.G. Restorative dental materials. St. Louis, MO: Mosby-Year Book; 1993. p. 248-270.

19. Celik C, Yuzugullu B, Erkut S, Yamanel K. Effects of mouthrinses on color stability of resin composites. Eur J Dent 2008 Oct;2:247-253.

20. Ferracane JL. Hygroscopic and hydrolytic effects in dental polymer networks. Dent Mater 2006 Mar;22(3):211-222.

21. Yiu CKY, King NM, Pashley DH, Suh BI, Carvalho RM, Carrilho MR, Tay FR. Effect of resin hydrophilicity and water storage on resin strength. Biomaterials 2004 Nov;25(26): 5789-5796.

22. Gohring TNY, Besek MJ, Schmidlin PR. Attritional wear and abrasive surface alterations of composite resins materials in vitro. J Dent 2002 Feb-Mar;30(2-3):119-127.

23. Davalloo R, Tavangar M, Darabi F, Pourhabibi Z, Alamouti NA. The surface hardness value of a light cured hybrid composite resin after 12 hours immersion in three alcohol-free mouthwashes. J Dentomaxillofac Radiol Pathol Surg 2013;2(4):1-6.

24. Khurshid Z, Zafar M, Qasim S, Shahab S, Naseem M, AbuReqaiba A. Advances in nanotechnology for restorative dentistry. Materials 2015;8(2):717-731.
25. Zafar MS, Ahmed N. Nanomechanical characterization of exfoliated and retained deciduous incisors. Technol Health Care 2014 Nov;22(6):785-793.

26. Zafar MS. A comparison of dental restorative materials and mineralized dental tissues for surface nanomechanical properties. Life Sci J 2014 Jan;11:19-24.

27. Zafar MS, Ahmed N. Nano-mechanical evaluation of dental hard tissues using indentation technique. World Appl Sci J 2013;28(10):1393-1399.

28. Sakaguchi, R.; Powers, J.; Craig's restorative dental materials. 13th ed. St. Louis, MO; ElsevierMosby Co; 2012. p. 48-190.

29. Yap AU, Mok BY. Effect of professionally applied topical fluorides on surface hardness of composite-based restoratives. Oper Dent 2002 Nov-Dec;27(6):576-581.

30. Zafar MS, Ahmed N. Therapeutic roles of fluoride released from restorative dental materials. Fluoride 2015 Jul-Sep;48(3): 184-194.

31. Ullah R, Zafar MS. Oral and dental delivery of fluoride: a review. Fluoride 2015 Jul-Sep;48(3):195-204.

32. Najeeb S, Khurshid Z, Zafar MS, Khan AS, Zohaib S, Martí JMN, Sauro S, Matinlinna JP, Rehman IU. Modifications in glass ionomer cements: nano-sized fillers and bioactive nanoceramics. Int J Mol Sci 2016 Jul;17(7):1134.

33. Zafar MS. Effects of surface pre-reacted glass particles on fluoride release of dental restorative materials. World Appl Sci J 2013;28(4):457-462.

34. Yap AUJ, Tan BWY, Tay LC, Chang KM, Loy TK, Mok BYY. Effect of mouthrinses on microhardness and wear of composite and compomer restoratives. Oper Dent 2003 Nov-Dec; 28(6):740-746.

35. Diaz-Arnold AM, Wistron DW, Swift EIJ. Topical fluoride and glass ionomer microhardness. Am J Dent 1995 Jun;8(3):134-136.

36. Diab M, Zaazou MH, Mubarak EH, Fahmy OMI. Effect of five commercial mouthrinses on the microhardness and color stability of two resin composite restorative materials. Aust J Basic Appl Sci 2007;1(4):667-674.

37. Dos Santos DM, Massurani L, Goiato MC, Zavanelli AC, Haddad MF, Moreno A, Vechiato-Filho AJ. Effect of different solutions on Knoop hardness of indirect composite resins. Dentistry 2014;4(3):208.

38. Festuccia MS, Garcia Lda F, Cruvinel DR, Pires-De-Souza Fde C. Color stability, surface roughness and microhardness of composites submitted to mouthrinsing action. J Appl Oral Sci 2012 Mar-Apr;20(2):200-205. 